\title{
The effect of unavailable donation opportunities on donation choice
}

\author{
Coby Morvinski ${ }^{1}$ (D)
}

Accepted: 28 December 2021 / Published online: 20 January 2022

(c) The Author(s) 2022

\begin{abstract}
In the context of charitable donation decisions, we demonstrate that adding information to the decision context about a fundraising campaign one cannot act on (i.e., an unavailable alternative) increases donations for the remaining, available campaign. At times, adding an unavailable alternative is even more effective at increasing the donation rate than adding an available alternative to the choice set, contradicting the normative assumption that having more options is better. We find preliminary evidence suggesting that the effect is driven by perceived impact-adding an unavailable alternative leads consumers to believe their donation will have a greater impact on the remaining cause. This investigation contributes to the consumer prosocial behavior literature by demonstrating the positive effect of unavailable alternatives on donation choice and identifying its extent and determinants. Future directions and practical implications for fundraising managers are discussed.
\end{abstract}

Keywords Prosocial behavior · Donation · Unavailable alternative

\section{Introduction}

When given an opportunity to help those in need, individuals sometimes act on this opportunity, whereas other times they do not, supporting the constructive nature of prosocial behavior. Although many situational factors influence a decision to give, contextual information often influences compliance with donation requests (Andreoni \& Payne, 2013; Frey \& Meier, 2004; Jenni \& Loewenstein, 1997). Although normative theories would predict that information not relevant to the donation's impact should not influence a donor's motivation, research consistently finds evidence to the contrary. Building on this work, we suggest that providing consumers with information about an unavailable fundraising opportunity increases

Coby Morvinski

cobym@bgu.ac.il

1 Guilford Glazer Faculty of Business and Management, Ben-Gurion University of the Negev, 8410501 Beer-Sheva, Israel 
contributions to an available option. As an example, imagine receiving a donation request from your alma mater, asking for donations to either their financial aid fund or their research fund, but also stating that the research fund is not currently accepting donations. Would you be more likely to donate to the financial aid fund than if no information about the unavailable research fund campaign had been presented? Although, normatively, information about the unavailable donation option should not influence your decision regarding whether to donate to the available option, we advance current knowledge by showing that unavailable alternatives increase donation choice. Further, we present preliminary evidence that information about unavailable donation options increases the donor's perceived impact on the available one.

\section{Unavailable alternatives}

Unavailable alternatives are choice options that are present in the choice set but cannot be selected at the time of the decision, and therefore are not actual options. Previous literature demonstrates that adding an unavailable alternative to the choice set may affect the attractiveness of a target alternative, a result that violates the regularity principle of classical choice theory (Luce, 2012; Tversky, 1972).

Perhaps, most relevant to marketers is the research on product scarcity demonstrating that consumers facing a stockout of an attractive product are less satisfied with their decision than similar consumers facing no stockout (e.g., Pizzi \& Scarpi, 2013). Consumers confronted with unavailability may also be more likely to defer consumption or choose a close substitute (Hamilton et al., 2014). However, a stockout may have a positive effect on decision satisfaction if it reduces the difficulty of making a product selection (Fitzsimons, 2000), and on purchase likelihood of the available product if it provides additional reasons for buying this product (Kramer \& Carroll, 2009).

The notion of unavailability may also be related to the research stream on phantom decoys (Farquhar \& Pratkanis, 1993; Pratkanis \& Farquhar, 1992), which shows that, in most situations, adding an unavailable alternative that asymmetrically dominates a target alternative increases the attractiveness of this alternative (Highhouse, 1996; Pettibone \& Wedell, 2000, 2007). Several recent studies, however, show that under some conditions, a dominating phantom decoy may diminish the attractiveness of the (dominated) target alternative (Scarpi \& Pizzi, 2013; Trueblood \& Pettibone, 2017). Note that in the current investigation, we do not attempt to identify and compare dominance of particular dimensional attributes of alternatives (i.e., no asymmetric dominance relationship exists within this conceptualization). Consequently, because phantom decoy effects are usually explained by changes in perceptions of the target option's dimensional attributes (Highhouse, 1996; Pettibone \& Wedell, 2000, 2007), an unavailable donation alternative is less likely to be seen as a phantom decoy within the current conceptualization.

Building on the above findings and other work on the constructive nature of consumer preference (Bettman et al., 1998; Payne et al., 1992), we suggest that unavailable alternatives may also affect consumer decisions in the less explored 
domain of charitable giving. In particular, we explore the effect of unavailable donation alternatives on the choice of the remaining donation alternative. Given the mixed results of unavailable-alternative effects, predicting the direction of the effect (if any) in the domain of charitable giving is not trivial. Here, we propose a mechanism unique to the domain of charitable giving that potentially underlies the effect: perceived impact.

\section{The role of perceived impact on prosocial behavior}

Donations made by individuals reached $\$ 309.66$ billion in 2019 , constituting about $72 \%$ of total giving (Giving USA Foundation, 2020). Scholars have proposed various self-interest and other-interest motivations for this wide-spread prosocial behavior (Deci \& Ryan, 2013; Meglino \& Korsgaard, 2004), including reputational benefits (Andreoni \& Petrie, 2004), the positive feeling of a warm glow (Andreoni, 1990; Park et al., 2017), and altruism borne form an intrinsic tendency to care for others (Warneken \& Tomasello, 2009).

Prior work also finds that donors are strongly motivated by the contribution they expect their donation to make-donors are more likely to give when they expect their gift to have a larger impact (Cryder et al., 2013a, b). For example, giving increases when donors are told their gift will be matched, which boosts the perceived impact of a donation (Karlan \& List, 2007). Past work further finds a "denominator effect," such that even if the total impact is held constant, individuals are more motivated to give to programs that make a larger proportionate impact (Baron, 1997; Fetherstonhaugh et al., 1997). This effect arises because helping a small fraction of a large group in need feels like one is making a lesser impact on the overall problem than helping the same number of people in a smaller group.

Similarly, in the context of donation alternatives, we propose that offering an inaccessible alternative may increase perceived donation impact, because, consistent with the denominator effect, a reduction in the size of the group that can receive donations increases the donation's perceived relative impact on the issue at hand. Importantly, we suggest that unavailable donation alternatives may also increase the perceived impact on seemingly unrelated causes. For example, people may respond more positively with a request to donate to homeless people when they also receive information about an inaccessible fundraising campaign for neglected animals. Moreover, the above prediction differs from many unavailable-alternative effects because it predicts a positive effect of an inaccessible fundraising alternative on the target alternative without assuming any preference of one alternative over another. As such, when the alternatives are similarly preferred, the effect should also hold when the available and unavailable donation offers are reversed. That is, people may also respond more positively with a request to donate to an animal shelter when they also receive information about an inaccessible fundraising campaign for homeless people. 


\section{Method}

After pre-testing the hypothesis that the addition of information about unavailable donation alternatives increases compliance with a target-donation request, Study 1 demonstrates that the effect is a result of the unavailability of the donation alternative rather than conformity to others' behavior. Then, in addition to refuting other explanations, Study 2 shows that adding an unavailable alternative can be more effective at increasing the donation rate than adding an available alternative to the choice set. Finally, Study 3 provides preliminary evidence that perceived impact on the remaining cause plays a role in the effect of unavailable alternatives on donation rate.

\section{Pretest}

One hundred and sixty-five undergraduate marketing students at IDC Israel completed the study as part of a class assignment. They read about a charity organization[s] and were asked to imagine that the student union is raising money for that charity and requesting donations of 100 NIS $(\sim 30)$ to the campaign. In the control conditions, one half of the participants were informed that the fundraising campaign is for a homeless shelter that provides temporary residence for homeless individuals while one half were informed that the donations were sought for an animal shelter dedicated to the rescue of unwanted, neglected, and abandoned dogs and cats. Those in the unavailable treatment conditions were informed that the student union was raising money for both the homeless and the animal shelters. However, some of them read that the campaign for the animal shelter had already reached its goal; thus, donations could only be made to the homeless shelters, while others learned that the campaign for the homeless shelter had already reached its goal; thus, they could only donate to the animal shelter. Therefore, the study consisted of two identically designed experiments, whereby the target campaign was either the homeless shelter or the animal shelter. We note that for each version of the study, the donation decisions in the control and treatment conditions were virtually the same since only the target charity was accepting donations in both conditions.

\subsection{Results}

Adding an unavailable alternative to the donation decision significantly increased donation choice. Across both versions of study, participants in the unavailable conditions were more likely to donate $(87 \%)$ than participants in the control conditions $(57 \%)\left(\chi^{2}[1]=18.60, p<0.001\right)$. The effect was robust to analyzing the results of each of version of the study, separately. Among participants who could only donate to the homeless shelter, adding information about an unavailable fundraising campaign for an animal shelter increased the donation rate from 65 to $90 \%$ $\left(\chi^{2}[1]=7.465, p=0.006\right)$. Similarly, among participants who could only donate to 
the animal shelter, adding information about an unavailable campaign for a homeless shelter increased the probability of giving from 49 to $84 \%\left(\chi^{2}[1]=11.53, p<0.001\right)$.

As the pretest results suggest, adding information about an unavailable fundraising campaign to a particular donation request may increase compliance with the request. The symmetry in the findings across target campaigns rules out the notion that this effect might be caused by preferences or dominance relationships in choice (i.e., phantom decoy).

\section{Study 1}

In the pretest, a donation alternative was stated to be unavailable because the campaign had already reached its goal. However, learning that another charity campaign has already reached its goal may signal that many people had donated. This social norm information is expected to increase donation likelihood because once they learn of (or infer) a norm, individuals are likely to follow it (Frey \& Meier, 2004; House et al., 2020; Shang \& Croson, 2009). Therefore, the reason for the campaign being unavailable (i.e., reaching its goal) may have played an important role in the pretest results, and the effect may not emerge in situations where the reason for the unavailability carries no information about other peoples' behavior. However, if the effect is grounded in the unavailability per se of the donation alternative, we should expect the effect to manifest under incidental unavailability devoid of social norm signals. Study 1 addresses this and explores potential mechanisms.

\subsection{Procedure}

We recruited 907 MTurk workers to complete Study 1 ( $M_{\mathrm{age}}=33.62,41 \%$ females $)$. Participants were randomly assigned to one of six 2 (target charity: homeless vs. animal) $\times 3$ (unavailability reason: control vs. goal-reached vs. computer-glitch) between-subject conditions. We used the same stimuli from the pretest. Specifically, participants in the control conditions read about either "Rescue Mission CentreA homeless shelter which provides temporary residence for homeless individuals" or about "Friends for Life Rescue-An animal shelter dedicated to the rescue of unwanted, neglected, and abandoned dogs and cats." Participants then imagined that the online community is raising money for these charities, allowing them to donate $\$ 3$ of their MTurk earnings. After receiving this information, participants reported what they would most likely do: "donate nothing" or "donate $\$ 3$ to the [homeless/ animal] shelter. Participants in the treatment conditions learned about both homeless and animal shelters, but only one of these fundraising campaigns were currently accepting donations: The goal-reached treatment conditions were similar as before where some participants could not donate to the animal shelter because this campaign already reached its fundraising goal, while others could not donate to the homeless shelter because of the same reason. In the computer-glitch treatment conditions, participants read that "Unfortunately, donations to the [homeless/animal] shelter cannot be accepted at this time due to temporary computer problems." Note 
Fig. 1 Study 1 donation rates

that the computer-glitch information provides no information about other people's behavior and, therefore, if the pretest results were driven by norm-conformity, we should not expect them to be replicated in the computer-glitch conditions. After making a donation decision, participants rated the perceived worthiness of the available and unavailable charities (two items each). In two additional items, participants rated other peoples' perceptions of the worthiness of the charities. Finally, we measured positive and negative affect following participants' donation decision (See Appendix A for all items).

\subsection{Results}

Study 1 replicated the pretest study: compared with the control conditions, participants' donation rates were higher when the donation requests also included information about an unavailable fundraising campaign. Importantly, these results were robust to the reasons for the campaign's unavailability. As Fig. 1 Panel A shows, across both versions of the study (i.e., donation to a homeless or to an animal shelter), participants in the goal-reached conditions (57.2\%), and participants in the computerglitch conditions $(60 \%)$ exhibited a significantly higher donation rates than those in the control conditions $(41 \%), \chi^{2}[1]=15.93, p<0.001$ and $\chi^{2}[1]=21.92, p<0.001$, respectively. Donation rates in the two unavailable alternative groups, goal-reached and computer-glitch, did not differ $\left(\chi^{2}[1]=0.50, p=0.48\right)$. A similar pattern of results was observed when analyzing each version of Study 1 separately (Fig. 1 Panel B). When the target charity was an animal shelter, participants in the goal-reached condition $(53.3 \%)$ and participants in the computer-glitch condition $(59.7 \%)$ were more likely to donate than participants in the control condition (48.6\%), although the effect was only directional in the former $\left(\chi^{2}[1]=0.65, p=0.42\right)$ and marginally significant in the latter, $\chi^{2}[1]=3.67, p=0.055$. The effects were much more unambiguous when the target charity was a homeless shelter: Participants in both the goal-reached condition (61\%) and the computer-glitch condition $(60.0 \%)$ exhibited significantly higher donation rates than participants in the control groups $(33.6 \%), \chi^{2}[1]=23.18$ and $\chi^{2}[1]=22.11, p s<0.001$, respectively. We ran an ANOVA of donation choice as a function of the three experimental conditions, controlling for target charity type (homeless or animal shelter), gender, age, and income level. This analysis revealed a main effect of condition, $F(2,900)=13.52, p<0.001, \eta_{p}{ }^{2}=0.03$. Target charity type $(p=0.50)$ and income level $(p=0.18)$ did not influence donation rates but females were more likely to donate than males $\left(F(1,900)=15.84, p<0.001, \eta_{p}{ }^{2}=0.01\right)$, and older participates were more likely to donate than younger participants, $F(1$, $900)=13.47, p<0.001, \eta_{p}{ }^{2}=0.01$. Importantly, a Tukey's HSD test confirmed that participants' donation rates in both goal-reached and computer-glitch conditions were significantly different than donation rates in the control conditions $(p$ 's $<0.001)$. There was no significant difference between the two treatment conditions $(p=0.75) .{ }^{1}$

\footnotetext{
1 Complete results of ANOVA tests are reported in Appendix D.
} 
A

0.6
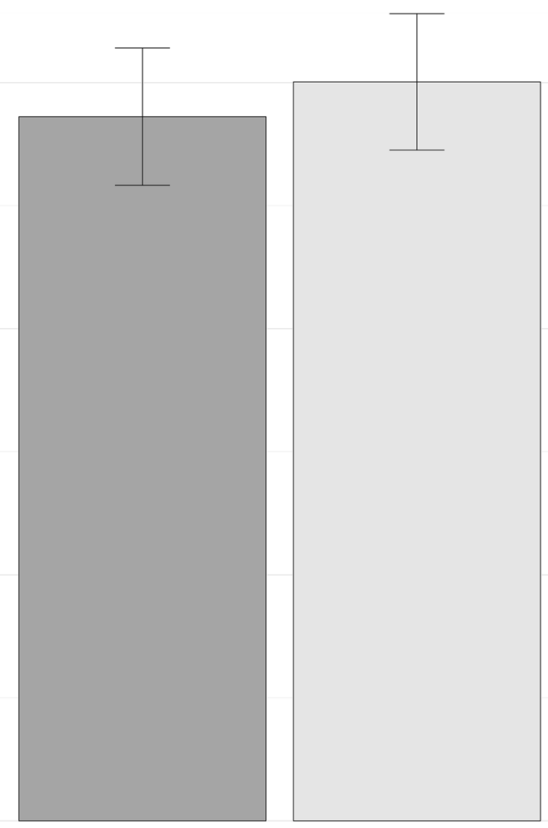

0.0

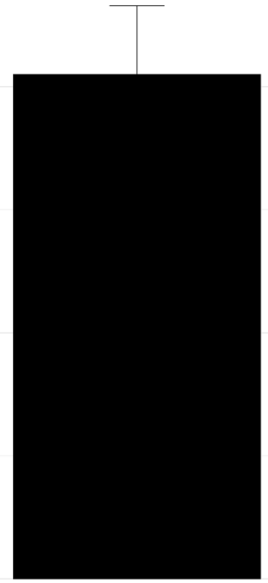

Control

Goal-reached

Computer-glitch

\section{Condition}

B

0.6
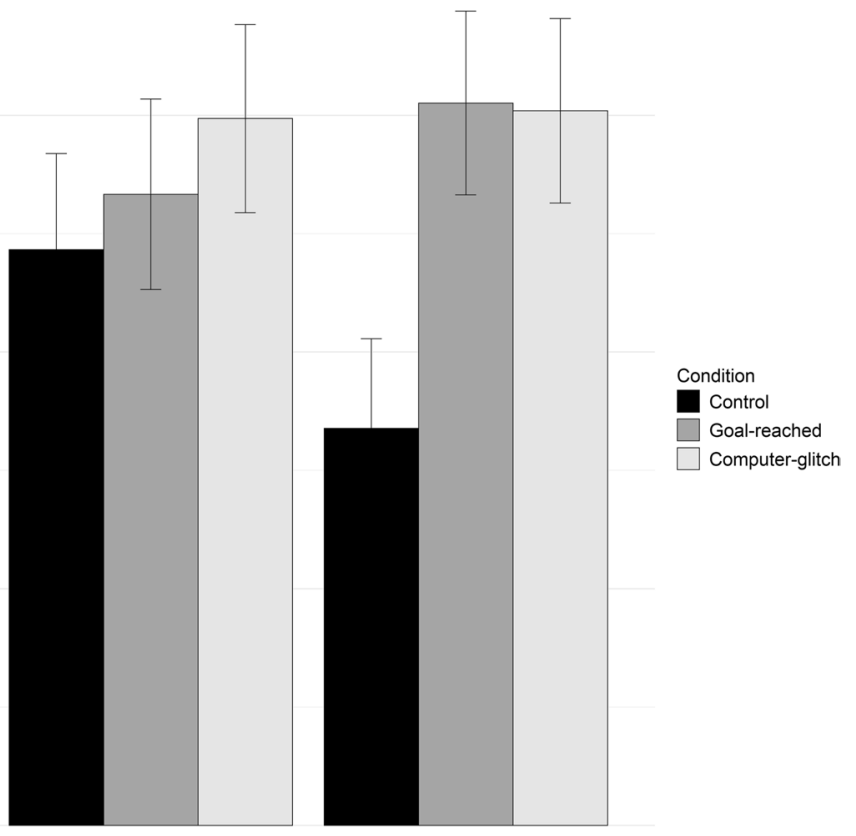

0.2

0.0

Animal

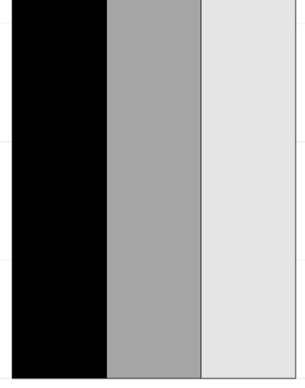

Goal-reached
Computer-glitch

Homeless

Charity 
The experimental condition revealed no effect on participants' attitudes toward the available charity or on the unavailable charity, and thus are not discussed (Analyses in Appendix D). Finally, compared with participants in the control conditions $(M=4.97, S D=1.79)$, participants in both goal-reached $(M=5.39, S D=1.55)$ and computer-glitch $(M=5.62, S D=1.53)$ conditions reported feeling significantly more positive (but not more negative) about their donation decision, $t(602)=3.04$, $p<0.01$ and $t(602)=4.74, p<0.001$, respectively. However, these effects completely disappear when considering only those who donated, suggesting that donation makes participants feel good about their decision to give. Therefore, we interpret these results as a reality check, in the sense that although the study was hypothetical, participants still accounted for their donation decision.

\subsection{Discussion}

Besides replicating the pretest results with a different population, the results of Study 1 suggest that social information about others' donation decisions is not essential for the observed effect. Furthermore, we found no evidence that changes in general attitudes toward the charity underlie the effect.

\section{Study 2}

The goal of Study 2 was threefold. First, it is likely that some participants in Study 1 would have donated to the unavailable campaign, say to the animal shelter, if this campaign was accepting donations. Therefore, a consistency-based account (Cialdini \& Trost, 1998) might also predict the observed results, as some participants might eventually donate to the available campaign, the homeless shelter, to remain consistent with their willingness to donate to the unavailable one, a donation offering they would have rejected otherwise. To test this possibility, we explore conditions under which participants are unlikely to prefer one alternative over the other. Specifically, in Study 2, the available and unavailable alternatives are simply different locations of the same charity. Second, one might plausibly argue that the observed effect is merely the result of presenting information about additional fundraising campaigns. That is, compared with a single donation offering, learning about multiple donation opportunities might lead people to form a more positive attitude toward helping others, which in turn increases their donation rate. According to this account, however, the donation rate of those who learn about two available donation alternatives should not differ from that of those who receive the same information about the two alternatives but one of the campaigns is out of reach. To test this alternative, we added a third condition where both donation alternatives were available. Finally, past research suggests that empathy is a key emotion motivating helping behaviors (Batson, 1987; Rathje et al., 2021), and people are more likely to donate when they deem the cause to be more important (Mathew et al., 2007; Pentecost \& Andrews, 2010). Therefore, in Study 2, we explore whether 
adding information about more donation alternatives increases feelings of empathy for those who can be helped or the perceived importance of the cause.

\subsection{Procedure}

We recruited 200 participants from Prolific Academic $\left(M_{\text {age }}=35.06,70 \%\right.$ females). Participants were randomly assigned to one of three experimental conditions: in addition to the standard control and unavailable conditions, participants in the available condition were requested to donate to one of two available campaigns. We used the same homeless shelter description as before, adjusted to British spelling. In this study, participants also received information about the location of the shelter. In the control condition, participants read that the "Rescue Mission Centre shelter is located in Filwood, Bristol" while in the available and unavailable conditions, they read that "There are currently two Rescue Mission centres operating in separate locations in Bristol: Hillfields and Filwood." All participants were asked to imagine that they could donate $£ 3$ of their Prolific earnings to one of these locations. In the unavailable condition, participants also learned that the Hillfields shelter could not accept donations due to a temporary computer problem, and therefore that they could only donate to the Filwood shelter. While participants in the control and unavailable conditions could only donate to the Filwood shelter, participants in the available condition could donate to either the Hillfields or the Filwood shelter. Before participants reported their donation decision, we measured participants' empathy for homeless people using a six-item scale (Batson, 1987). Following their donation decisions, participants also completed a 3-item scale to measure perceived importance of the cause (Appendix B).

\subsection{Results}

\subsubsection{Manipulation check}

Among participants who chose to donate $£ 3$ in the available condition, donations to the Filwood and Hillfields campaigns were equally divided (12 donations each). Therefore, we conclude that participants did not prefer one campaign over the other.

\subsubsection{Main results}

To calculate donation rate in the available condition, we marked as a donor any participant who donated to either the Filwood or the Hillfields shelter. Figure 2 depicts the main results. While $22.4 \%$ of participants in the control condition donated $£ 3$ to the Filwood shelter, donation rates to this location reached $53 \%$ when participants also received information about a temporarily unavailable fundraising campaign for the Hillfields shelter, $\chi^{2}[1]=13.31, p<0.001$. Importantly, participants in 
0.6

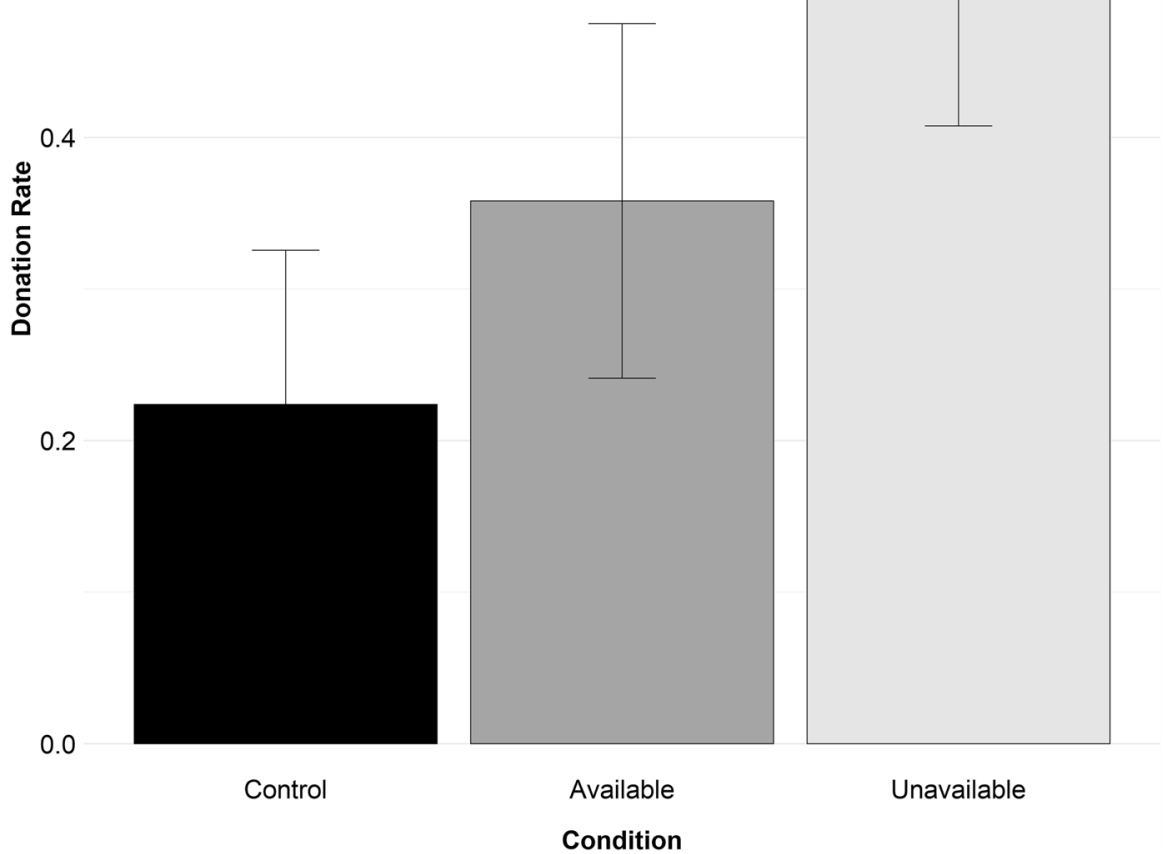

Fig. 2 Study 2 donation rates

the unavailable condition were also more likely to donate than those in the available condition $(35.8 \%), \chi^{2}[1]=3.99, p=0.046$. These results suggest that the effect largely stems from the unavailability state of the additional alternative, rather than merely its inclusion in the decision structure. Nevertheless, compared with the control condition, introducing a second available donation alternative marginally increased participants' willingness to donate, $\chi^{2}[1]=2.93, p=0.087$. However, comparing donation rates to the Filwood location (the shared alternative of both conditions) reveals no difference, $M_{\text {control }}=0.22 .4 \%, M_{\text {available-Filwood }}=17.9 \%, \chi^{2}[1]=0.41$, $p=0.52$. That is, participants in the available condition were as likely to donate to the Filwood campaign as those in the control condition. The result of the empathy measure suggests that unavailable-alternative manipulations did not affect participants' feelings of empathy toward the general target of the campaign-homeless people. Finally, participants in the unavailable condition thought that helping homeless people was more important, relative to participants in the control condition $(p=0.037)$ but not more than participants in the available condition (Appendix D for analyses of all additional measures). 


\subsection{Discussion}

Beyond replicating the previous findings using practically indistinguishable donation options for the same cause, the results of Study 2 suggest that a consistencybased explanation, where participants who would otherwise prefer to donate to the unavailable campaign, ultimately donated to the available campaign because they already decided to donate, is less likely. Also, Study 2 finds no evidence that the effect is merely a result of receiving information about an additional fundraising campaign as participants in the unavailable condition were more likely to donate than participants in the available condition. Finally, while we found no evidence that adding an unavailable donation alternative induced more empathy for the target population, perceived importance of helping the target population may play some role in the observed effect. However, we have no theoretical basis for this result.

\section{Study 3}

Our final study was designed to test the proposed mechanism according to which unavailable donation alternatives may increase the perceived impact of the available option, thus increasing donation probability (vs. control). We tested this explanation against other perceptions known to influence donations: responsibility and need to support the cause. For generalizability, Study 3 used different fundraising purposes for the same charity (i.e., funds), and the provided no particular reason justifying unavailability.

\subsection{Procedure}

We recruited 402 participants from Prolific Academic $\left(M_{\text {age }}=34.73,65 \%\right.$ females $)$. The study design, exclusions, and analyses were pre-registered (https://aspredicted. org/UEI_KWM). Similar to Study 2, participants first learned about the Rescue Mission Centre and then indicated how likely they would be to donate $£ 3$ to this charity. However, in Study 3, we introduced different funds for that charity and counterbalanced their unavailability. Specifically, in the control conditions, one half of the participants were requested to donate to the centre's emergency assistance fund while the second half were requested to donate to the centre's hot meals fund. Among the participants in the unavailable conditions, one half were requested to donate to the centre's emergency assistance fund, but also learned that the hot meal fund was currently unavailable, and one half were offered the reverse option. Therefore, participants were randomly assigned to one of four donation conditions. In this study, we did not specify the reason for a fund's unavailability. After learning about the donation opportunities but before reporting their donation choice, all participants rated the perceived impact of their donation, responsibility to support the cause, and need for supporting the charity, as all these factors are known to influence giving (Appendix C). Following their donation decision, participants also completed an attention check question. 


\subsection{Results}

\subsubsection{Main results}

We excluded 54 participants who failed the attention check. However, the full data results remain virtually the same (Appendix D). Overall, 59.2\% of the participants reported they would donate $£ 3$. As expected, and regardless of the specific fund (emergency assistance vs. hot meal), donation rates increased when the donation options included an unavailable alternative. When requested to donate to the emergency assistance fund, $46.6 \%$ donated when there was no unavailable alternative in the choice set, whereas $67.5 \%$ donated when the offer also included an unavailable donation alternative to the hot meal fund, $\chi^{2}(1)=6.76, p=0.009$. Similarly, though only directional, $58.1 \%$ donated to the hot meals fund in the control condition, compared to $64.8 \%$ when the request also mentioned the emergency assistance fund as an unavailable option $(p=0.45)$. Given that the directions of both control-treatment pairs were the same, the combined dataset produces a replication of the previously observed effect, $M_{\text {control }}=52.3 \%, M_{\text {unavailable }}=66.1 \%, \chi^{2}(1)=6.29, p=0.012$.

\subsubsection{Mechanisms}

For each participant, we averaged the four impact items to create a perceived impact index $(\alpha=0.93)$. Similarly, we created perceived responsibility $(r=0.79)$ and perceived need $(\alpha=0.78)$ indices from the responsibility and the needs items, respectively. To shed light on the mechanism underlying the effect, we first ran a parallel mediation model using bootstrapping with bias-corrected confidence estimates and 5,000 resamples, with condition as the independent variable (control vs. unavailable); impact, responsibility, and need as the moderators; and donation choice as the dependent variable. This model indicated that the effect of the unavailable treatment was mediated by perceived impact $(\mathrm{CI}[0.26,0.88])$, but not by other measures. Next, we ran a separate mediation model for each of the above mechanisms using the same dependent and independent variable. Once again, the model revealed a significant indirect effect of perceived impact $(\mathrm{CI}[0.36,1.05])$. Seeing a donation offer with an unavailable alternative (versus without) increased participants' sense of perceived impact, $\beta=0.59$, $p<0.001$, which in turn drove an increase in donation probability, $\beta=1.15, p<0.001$. Confidence intervals for responsibility and need mediators contained zero.

\section{General discussion}

Three studies and one pretest provide converging evidence for the effect of information about unavailable donation options on increased compliance with a donation request. The effect was robust to different unavailability justifications and emerged even when no justification for unavailability was provided. Additionally, we were able to refute dominating alternative explanations such as conformity with social norms and psychological consistency. Finally, our findings offer preliminary evidence for the underlying mechanism: an increase in the perceived impact of the 
donation. These findings expand our understanding of the constructive nature of consumer prosocial decision-making by demonstrating a new factor-an unavailable donation alternative - that positively affects donation choice. Our findings also contribute to the growing marketing literature on unavailable alternatives by showing that the effect of these alternatives on the remaining option extends beyond traditional purchase decisions and product valuations.

Future research could more closely examine the conditions under which the above effect is expected to manifest. For example, most studies on unavailable alternatives and on phantom decoys call attention to preference or dominance relationships in judgment and in choice and usually find a positive effect of superior, but not inferior, inaccessible alternatives. Although in our studies, unavailable donation alternatives were similarly preferred, we did not set out to directly investigate potential moderating effects of different preference relationships. On the one hand, a decision-maker may ignore undesirable alternatives, and thus should not be influenced by them, particularly when they become unavailable, suggesting a potential boundary condition. On the other hand, vastly inferior unavailable alternatives may trigger other processes such as a contrast effect, namely, an increase in the relative attractiveness of the remaining alternative, which should increase its choice rate. A contrast effect may also reduce the relative attractiveness of the remaining option if the unavailable alternative is extremely superior, thus offsetting the positive effect that this alternative would have had otherwise. Therefore, future studies could explore the dynamic role a preference relationship may play in moderating the effect of unavailable donation alternatives. For example, participants in our studies who believe homelessness is a personal choice might have been affected differently by the presence of an unavailable option to donate to the homeless shelter. Similarly, the degree of psychological closeness individuals feel toward the donation targets can also change the relative attractiveness between the available and unavailable alternatives (e.g., a donation request from their alma mater vs. from another school), which may consequently moderate the effect.

Future research could also investigate other moderators of the effect. For example, past research has shown that alternatives that become unavailable after being selected affect people's consideration of the remaining, previously rejected options (Potter \& Beach, 1994) and reduce consumer satisfaction and repatronage intentions (Pizzi \& Scarpi, 2013). An examination of the effect in a setting where donation alternatives become unavailable after being selected would be interesting. Self-integrity concerns might lead the decision-maker to act in way that is consistent with their previous judgment by donating to the available cause. Alternatively, an individual who decided to donate to a campaign that subsequently became unavailable might feel justified to reject the request to donate to the available campaign (Khan \& Dhar, 2006; Mazar \& Zhong, 2010). Factors that are known to influence the perceived impact of one's donation on the cause may also moderate the effect. For example, past research suggests that people believe that their contribution has a greater impact when they can help a charity that is close to (vs. far from) its fundraising goal (Cryder et al., 2013a, b). It is therefore plausible that goal proximity may moderate the effect. For example, the increase in perceived impact observed in Study 3 could be offset if the unavailable alternative is significantly more distal from its goal, compared with the goal proximity of the available alternative. 
The above results may have practical implications for fundraisers who may benefit from presenting information about unavailable donation campaigns when such information exists. For example, online fundraisers may be wise to present information on expired or on-hold campaigns, or campaigns that have already reached their goal, in conjunction with information on the currently running campaigns, similar to the way travel-booking websites occasionally present unavailable choice options in their search results. In the offline world, nonprofit organizations that send donation requests to potential donors can also increase their response rate if the request additionally includes information about other unavailable fundraising campaigns, such as previous campaigns operated by the organization or campaigns that are only available in other geographical areas.

Supplementary Information The online version contains supplementary material available at https://doi. org/10.1007/s11002-021-09613-4.

Funding This work was supported by the Israel Science Foundation (ISF Grant 766/19).

\section{Declarations}

Compliance with Ethicals All studies were approved by the institution's IRB.

Open Access This article is licensed under a Creative Commons Attribution 4.0 International License, which permits use, sharing, adaptation, distribution and reproduction in any medium or format, as long as you give appropriate credit to the original author(s) and the source, provide a link to the Creative Commons licence, and indicate if changes were made. The images or other third party material in this article are included in the article's Creative Commons licence, unless indicated otherwise in a credit line to the material. If material is not included in the article's Creative Commons licence and your intended use is not permitted by statutory regulation or exceeds the permitted use, you will need to obtain permission directly from the copyright holder. To view a copy of this licence, visit http://creativecommons.org/licen ses/by/4.0/.

\section{References}

Andreoni, J. (1990). Impure altruism and donations to public goods: A theory of warm-glow giving. The Economic Journal, 100(401), 464-477.

Andreoni, J., \& Payne, A. A. (2013). Charitable giving. In Handbook of public economics (Vol. 5, pp. 1-50). Elsevier.

Andreoni, J., \& Petrie, R. (2004). Public goods experiments without confidentiality: a glimpse into fundraising. Journal of Public Economics, 88(7-8), 1605-1623.

Baron, J. (1997). Confusion of relative and absolute risk in valuation. Journal of Risk and Uncertainty, 14(3), 301-309.

Batson, C. D. (1987). Prosocial motivation: Is it ever truly altruistic? Advances in Experimental Social Psychology, 20, 65-122.

Bettman, J. R., Luce, M. F., \& Payne, J. W. (1998). Constructive consumer choice processes. Journal of Consumer Research, 25(3), 187-217.

Cialdini, R. B., \& Trost, M. R. (1998). Social influence: Social norms, conformity and compliance.

Cryder, C. E., Loewenstein, G., \& Scheines, R. (2013a). The donor is in the details. Organizational Behavior and Human Decision Processes, 120(1), 15-23.

Cryder, C. E., Loewenstein, G., \& Seltman, H. (2013b). Goal gradient in helping behavior. Journal of Experimental Social Psychology, 49(6), 1078-1083. 
Deci, E. L., \& Ryan, R. M. (2013). Intrinsic motivation and self-determination in human behavior. Springer Science \& Business Media.

Farquhar, P. H., \& Pratkanis, A. R. (1993). Decision structuring with phantom alternatives. Management Science, 39(10), 1214-1226.

Fetherstonhaugh, D., Slovic, P., Johnson, S., \& Friedrich, J. (1997). Insensitivity to the value of human life: A study of psychophysical numbing. Journal of Risk and Uncertainty, 14(3), 283-300.

Fitzsimons, G. J. (2000). Consumer response to stockouts. Journal of Consumer Research, 27(2), 249-266.

Frey, B. S., \& Meier, S. (2004). Social comparisons and pro-social behavior: Testing "conditional cooperation" in a field experiment. American Economic Review, 94(5), 1717-1722.

Giving USA Foundation. (2020). https://givingusa.org/giving-usa-2020-charitable-giving-showed-solidgrowth-climbing-to-449-64-billion-in-2019-oneof-the-highest-years-for-giving-on-record/

Hamilton, R. W., Thompson, D. V., Arens, Z. G., Blanchard, S. J., Häubl, G., Kannan, P. K., ... Thomas, M. (2014). Consumer substitution decisions: An integrative framework. Marketing Letters, 25(3), 305-317.

Highhouse, S. (1996). Context-dependent selection: The effects of decoy and phantom job candidates. Organizational Behavior and Human Decision Processes, 65(1), 68-76.

House, B. R., Kanngiesser, P., Barrett, H. C., Broesch, T., Cebioglu, S., Crittenden, A. N., ... \& Silk, J. B. (2020). Universal norm psychology leads to societal diversity in prosocial behaviour and development. Nature Human Behaviour, 4(1), 36-44.

Jenni, K., \& Loewenstein, G. (1997). Explaining the identifiable victim effect. Journal of Risk and Uncertainty, 14(3), 235-257.

Karlan, D., \& List, J. A. (2007). Does price matter in charitable giving? Evidence from a large-scale natural field experiment. American Economic Review, 97(5), 1774-1793.

Khan, U., \& Dhar, R. (2006). Licensing effect in consumer choice. Journal of Marketing Research, 43(2), $259-266$.

Kramer, T., \& Carroll, R. (2009). The effect of incidental out-of-stock options on preferences. Marketing Letters, 20(2), 197-208.

Luce, R. D. (2012). Individual choice behavior: A theoretical analysis. Courier Corporation.

Mathew, S. M., King, M. R., Glynn, S. A., Dietz, S. K., Caswell, S. L., \& Schreiber, G. B. (2007). Opinions about donating blood among those who never gave and those who stopped: A focus group assessment. Transfusion, 47(4), 729-735.

Mazar, N., \& Zhong, C. B. (2010). Do green products make us better people? Psychological Science, 21(4), 494-498.

Meglino, B. M., \& Korsgaard, A. (2004). Considering rational self-interest as a disposition: Organizational implications of other orientation. Journal of Applied Psychology, 89(6), 946.

Park, S. Q., Kahnt, T., Dogan, A., Strang, S., Fehr, E., \& Tobler, P. N. (2017). A neural link between generosity and happiness. Nature Communications, 8(1), 1-10.

Payne, J. W., Bettman, J. R., \& Johnson, E. J. (1992). Behavioral decision research: A constructive processing perspective. Annual Review of Psychology, 43(1), 87-131.

Pentecost, R., \& Andrews, L. (2010). Differences between students and non-students' willingness to donate to a charitable organisation. International Journal of Nonprofit and Voluntary Sector Marketing, 15(2), 122-136.

Pettibone, J. C., \& Wedell, D. H. (2000). Examining models of nondominated decoy effects across judgment and choice. Organizational Behavior and Human Decision Processes, 81(2), 300-328.

Pettibone, J. C., \& Wedell, D. H. (2007). Testing alternative explanations of phantom decoy effects. Journal of Behavioral Decision Making, 20(3), 323-341.

Pizzi, G., \& Scarpi, D. (2013). When out-of-stock products DO backfire: Managing disclosure time and justification wording. Journal of Retailing, 89(3), 352-359.

Potter, R. E., \& Beach, L. R. (1994). Decision making when the acceptable options become unavailable. Organizational Behavior and Human Decision Processes, 57(3), 468-483.

Pratkanis, A. R., \& Farquhar, P. H. (1992). A brief history of research on phantom alternatives: Evidence for seven empirical generalizations about phantoms. Basic and Applied Social Psychology, 13(1), $103-122$.

Rathje, S., Hackel, L., \& Zaki, J. (2021). Attending live theatre improves empathy, changes attitudes, and leads to pro-social behavior. Journal of Experimental Social Psychology, 95, 104138.

Scarpi, D., \& Pizzi, G. (2013). The impact of phantom decoys on choices and perceptions. Journal of Behavioral Decision Making, 26(5), 451-461. 
Shang, J., \& Croson, R. (2009). A field experiment in charitable contribution: The impact of social information on the voluntary provision of public goods. The Economic Journal, 119(540), 1422-1439.

Trueblood, J. S., \& Pettibone, J. C. (2017). The phantom decoy effect in perceptual decision making. Journal of Behavioral Decision Making, 30(2), 157-167.

Tversky, A. (1972). Elimination by aspects: A theory of choice. Psychological Review, 79(4), 281.

Warneken, F., \& Tomasello, M. (2009). The roots of human altruism. British Journal of Psychology, $100(3), 455-471$.

Publisher's Note Springer Nature remains neutral with regard to jurisdictional claims in published maps and institutional affiliations. 